Iranian

Volume 12 Number 6 (December 2020) 516-521

\title{
Molecular detection of Propionibacterium acnes in biopsy samples of intervertebral disc with modic changes in patients undergoing herniated disc surgery
}

\author{
Sharif Najafi', Pedram Mahmoudi', Seyed Alireza Bassampour ${ }^{2}$, Babak Shekarchi ${ }^{3}$, Mohammad \\ Soleimani ${ }^{4}$, Mojgan Mohammadimehr ${ }^{5 *}$ \\ ${ }^{l}$ Department of Physical Medicine and Rehabilitation, Clinical Biomechanics and Ergonomics Research \\ Center, Aja University of Medical Sciences, Tehran, Iran \\ ${ }^{2}$ Department of Orthopedic, Aja University of Medical Sciences, Tehran, Iran \\ ${ }^{3}$ Department of Radiology, Aja University of Medical Sciences, Tehran, Iran \\ ${ }^{4}$ Department of Microbiology, Aja University of Medical Sciences, Tehran, Iran \\ ${ }^{5}$ Department of Laboratory Sciences, Faculty of Paramedical Sciences, Aja University of Medical Sciences, \\ Tehran, Iran
}

Received: June 2020, Accepted: November 2020

\begin{abstract}
Background and Objectives: Recent studies have hypothesized that sterile disc infection with the anaerobic Propionibacterium acnes, recently renamed Cutibacterium acnes, occurs in people with intervertebral disc (IVD) herniation. This study aimed to examine the presence of P. acnes in patients who have Low back pain (LBP) with Modic changes observed in their Magnetic Resonance Imaging (MRI).

Materials and Methods: Thirty-seven patients who were candidates for surgery due to disc herniation and demonstrated Modic changes in MRI were included in the study. Before the surgery, the level of pain in patients was assessed using the visual analog score (VAS). All patients were asked to fill in the Oswestry Low Back Pain Disability Questionnaire. Intervertebral disc changes observed in MRI were recorded for all patients. Then, during surgery, sterile intervertebral disc samples were taken. $P$. acnes detection was performed using PCR in the laboratory. Data analysis with Chi-squared test, independent samples t-test, and Mann-Whitney U test in SPSS 18.0.

Results: The mean age of 37 patients equaled 43.64 years and the mean duration of symptoms was 11.05 months. In molecular examination, of the 37 individuals, the genome of $P$. acnes was positive in 23 cases (62.2\%) and negative in 14 (37.8\%). The relationship between VAS, disability score, changes in MRI, and patients' age with the positivity of the intervertebral disc sample was also assessed. Of these variables, only age was significantly correlated with the positive molecular finding, such that with an increase in age, the probability of positive findings was increased $(\mathrm{p}=0.022)$.

Conclusion: Based on the results, lumbar disc infection with P. acnes may play a significant role in causing Modic changes and the progression of the disease in patients with LBP.
\end{abstract}

Keywords: Intervertebral disc; Low back pain; Propionibacterium acnes; Cutibacterium acnes

*Corresponding author: Mojgan Mohammadimehr, Ph.D, Department of Laboratory Sciences, Faculty of Paramedical Sciences, Aja University of Medical Sciences, Tehran, Iran.

Tel: $+98-43822995$

Fax: +98-43822991

Email:m.mohammadimehr@ajaums.ac.ir

\section{INTRODUCTION}

During the past decades, low back pain (LBP) has been one of the leading causes of disease burden in developed and developing countries. LBP is widespread and the most debilitating factor in the workplace. LBP places a significant economic burden on 
governments, especially in terms of health system costs, lost working days, reduced productivity, and increased disability (1). LBP is a highly prevalent disease, that $50-80 \%$ of adults experience at some point in their life. It is believed that adults at working age are the most vulnerable group of LBP (2). Modic changes (MC) are in fact the edema of intervertebral disc (IVD) which is observed frequently in people with LBP. Therefore, they may play a key role in LBP pathogenesis $(3,4) . \mathrm{MC}$ is visible only in Magnetic Resonance Imaging (MRI) (5). Two pathologies have been introduced for MC, including mechanical and infectious causes. In mechanical cause, the degeneration of IVD causes the loss of the soft nuclear material, and reduces the height of the disc, eventually causing hydrostatic pressure. These changes impose a heavy pressure on the endplates, thereby causing the formation of microfractures. MC may be due to an edema which is secondary to fractures and the resulting inflammation, or due to an inflammation caused by the release of cytokines from the nucleus pulpous in the matrix of fracture (6). In the second group of patients, infections occur during surgeries in which the central part of the disc is removed in a completely sterilized manner, the growth of anaerobic Propionibacterium acnes (renamed as Cutibacterium acnes) and Corynebacterium propinquum has been observed in $53 \%$ of the samples (7). P. acnes is a Gram-positive aero tolerant, anaerobic bacillus that produces propionic acid as a metabolic byproduct. It is ubiquitous in sebaceous glands of human beings, and derives energy from fatty acids found in sebum (8). P. acnes is frequently found in hair follicles on the surface of the skin and in the oral cavity. This bacterium often enters the blood flow while brushing the teeth, but cannot threaten health due to the aerobic medium of the blood $(9,10)$. Macrophages are shown to be the most important immune factors in the process of absorption of herniated discs. Numerous studies using immunohistochemistry have found the presence of macrophages in herniated IVD tissue samples. These cells have the ability to actively phagocytize herniated tissue and process it in their lysosomes, which are full of collagen-degrading enzymes (11).

Since the central part of the disc is an appropriate anaerobic environment for the growth of this bacterium, it is probable that bacteria with a low virulence would gradually enter the IVD and cause infection (4). Some studies have shown that patients with herniat- ed IVD and MC positively respond to antibiotics (12).

The mentioned factors all fortify the hypothesis of the presence of infection for causing MC. The present study examined the presence of $P$. acnes in people who have LBP and MC observed in their MRI. The main goal of this study was to investigate DNA of $P$. acnes in the biopsy sample of IVD with MC in patients undergoing herniated disc surgery.

\section{MATERIALS AND METHODS}

Study design. This cross-sectional study examined the role of bacterial agents in causing lumbar disc herniation. It was conducted on 37 patients visiting Imam Reza Hospital in Tehran from January to July in 2017, who were diagnosed with herniated disc and underwent surgery. Exclusion criteria included: history of any vertebral surgery, history of trauma or fractures in the vertebral column, history of infection in the vertebral column, diseases reducing the immune system, rheumatological diseases, diabetes mellitus, consumption of antibiotics in the past 60 days, and the age of $<22$ and $>75$ years.

Collection of biopsies. Specimens were collected in the operating room by the surgeon under sterile conditions. Specimens were immediately transferred to tubes containing the thioglycolate broth culture medium and sent to the laboratory.

Molecular identification of Propionibacterium acnes by PCR. The culture tubes were incubated at $37^{\circ} \mathrm{C}$ for 14 days, and then centrifuged at $2000 \mathrm{rpm}$ for $3 \mathrm{~min}$. The supernatant was transferred into a new tube, and DNA was extracted using the DNA extraction kit (DNA، EZ-10 Spin column genomic DNA minipreps, Bio Basic, Canada) based on the manufacturer guidelines. The extracted genomic DNA was qualitatively and quantitatively analyzed using electrophoresis agarose gel and spectrophotometry. To perform PCR, the primers and method proposed by Albert et al. (13) and Sfanos and Isaacs (14) were used. For this purpose, $P$. acnes $16 \mathrm{~S}$ rDNA specific primers including PA-1 (5'-GGCACACCCATCTCTGAGCAC) and PA-2 (5'-GGGTTGTAAACCGCTTTCGCTG) were used to amplify a $600 \mathrm{bp}$ fragment (15).

PCR reaction contained $2.5 \mu \mathrm{l}$ of $10 \times \mathrm{PCR}$ buffer (10 mM Tris $\mathrm{HCl} \mathrm{pH} 8.3,3.5 \mathrm{mM} \mathrm{MgCl}_{2}, 25 \mathrm{mM}$ 
$\mathrm{KCl}), 0.5 \mu \mathrm{l}$ of $10 \mu \mathrm{M}$ PA-F' primer, $0.5 \mu \mathrm{l}$ of $10 \mu \mathrm{M}$ PA-R primer, $0.2 \mu \mathrm{l}$ of dNTPs (10 mM of each), $1 \mu \mathrm{l}$ of Taq DNA polymerase ( $1 \mathrm{U} / \mu \mathrm{l}), 19.8 \mu \mathrm{l}$ of sterilized distilled water and $2 \mu \mathrm{l}$ of the template DNA was prepared. The DNA extracted from $P$. acnes ATCC 6919 (Pasteur Institute of Iran) was used as positive control, while the addition of distilled water instead of the model DNA was used as negative control. The following thermal program was adopted for the PCR reaction: Initial denaturation at $94^{\circ} \mathrm{C}$ for $4 \mathrm{~min}, 35 \mathrm{cy}-$ cles including denaturation at $94^{\circ} \mathrm{C}$ for $30 \mathrm{~s}$, annealing at $54^{\circ} \mathrm{C}$ for $30 \mathrm{~s}$, extension at $72^{\circ} \mathrm{C}$ for $1 \mathrm{~min}$ and the final extension at $72^{\circ} \mathrm{C}$ for $4 \mathrm{~min}$. The $2 \%$ agarose gel containing $1 \mu \mathrm{g} / \mathrm{ml}$ of ethidium bromide in the TAE (40 mM Tris, $1 \mathrm{mM}$ EDTA, 0.1\% (v/v) glacial acetic) buffer and $10 \mathrm{~V}$ voltage were used for electrophoresis of PCR products as well as the $100 \mathrm{bp}$ DNA marker.

Statistical analysis. The quantitative data were analyzed using descriptive and inferential statistics. In descriptive statistics, quantitative data (mean, SD, minimum, maximum, first quartile, median, and third quartile) are reported, and qualitative data are reported in terms of number and percent. Chi-squared test, independent samples t-test, and Mann-Whitney U test in SPSS 18.0 were employed to determine the relationship between variables. The significance level was considered $\mathrm{p}<0.05$ for all statistical tests.

Ethical considerations. The study was approved by the Vice Chancellor for Research, Aja University of Medical Sciences no:92/93/52. To observe ethical considerations, the method of the study was fully explained to the participants at the outset, and written informed consent for participation was obtained from them.

\section{RESULTS}

In this study, 37 patients who had undergone surgery in Imam Reza Hospital due to lumbar disc herniation were included. Mean age of participants was 43.64 years with the SD of 9.31 years. The youngest patient was 25 years old, while the oldest was 60 years old. Mean duration of symptoms was 11.05 months with the SD of 5.84 months. Prior to the surgery, the median of the VAS score was 7 with the inter-quartile range of 6.5-8. Based on the results, the highest level of disability was 68 and the lowest was 48 with the median of 60 and the inter-quartile range of 56-64. Assessment of patients using MRI revealed that all of them had MC. MRI findings in terms of disc hernia were classified in three groups: bulging, extrusion, and protrusion. Accordingly, 20 patients (54.1\%) had IVD protrusion, $13(35.1 \%)$ had extrusion, and four (10.8\%) only had disc changes in the form of bulging. In PCR molecular examination, of the 37 individuals, the genome of $P$. acnes was positive in 23 cases (62.2\%) and negative in 14 (37.8\%). Patients in whose disc sample the genome of $P$. acnes was observed had a higher mean age (46.34 years with the SD of 8.09). On the other hand, patients with negative samples had a mean age of 39.21 years with the SD of 9.72, and this difference was significant based on independent samples t-test $(\mathrm{p}=0.022)$.

Based on the chi-squared test, no relationship was found between MRI findings and the results of molecular examination of biopsy samples $(p=0.694)$ (Table 1). Comparison of VAS and the level of disability based on the Oswestry Low Back Pain Disability Questionnaire tested by Mann-Whitney U test showed no significant difference between patients with positive and negative findings $(p=0.115$, $\mathrm{p}=0.448$, respectively), only there was a significant difference between the age of patients with positive PCR and negative PCR findings $(p=0.0221)$ (Table 2).

Table 1. MRI findings in groups with positive and negative PCR

\begin{tabular}{llll}
\hline & Positive PCR & Negative PCR & p-value \\
\hline MRI findings & & & 0.694 \\
Protrusion & $13(56.5 \%)$ & $7(50.0 \%)$ & \\
Extrusion & $7(30.4 \%)$ & $6(42.9 \%)$ & \\
Bulging & $3(13.0 \%)$ & $1(7.1 \%)$ & \\
\hline
\end{tabular}

Table 2. Comparison of age, VAS score, and disability score between patients with positive and negative PCR

\begin{tabular}{llll}
\hline & Positive PCR & Negative PCR & p-value \\
\hline Age (mean) & $46.34 \pm 8.09$ & $39.21 \pm 9.75$ & 0.0221 \\
VAS (median) & $7(7-8)$ & $7(6-8)$ & 0.1152 \\
$\begin{array}{l}\text { Disability score } \\
\text { (median) }\end{array}$ & & $61(50-64)$ & 0.4482 \\
\hline
\end{tabular}

Computed by independent samples t-test

Computed by Mann-Whitney U test 


\section{DISCUSSION}

In this study, 37 patients who had undergone surgery in Imam Reza Hospital due to lumbar disc herniation were examined. In the sterile conditions of the operating room, samples of IVD were prepared and examined in terms of the presence of the bacterium. In $62.2 \%$ of the samples, the genome of $P$. acnes was present. The relationship between variables and the PCR results were also investigated; only age was positively correlated with positive PCR.

Similar to the present study, many other studies have been conducted in recent years, most of which reporting similar results $(7,12,16-18)$. Wedderkopp et al. reported that $8.3 \%$ of the biopsy samples (from 24 samples) showed bacterial growth (19). Based on the results reported by Agarwal et al. positive culture after discectomy was identified in 10 cases, i.e. $19.2 \%$ of patients. P. acnes was isolated from 7 (13.5\%) patients, and a mixed microflora (Streptococcus and Staphylococcus) was identified (16).

According to Albert et al. $46 \%$ of the 61 patients with lumbar disc herniation, the microorganism existed in the extruded nuclear tissue. The cultured microorganism was mostly the anaerobic $P$. acnes. The findings of this study may confirm the theory that the incidence of type I MC in vertebrae adjacent to the previously herniated disc may occur around the edema of an infected disc (13). In a study by Arndt et al. patients with disc degeneration were studied. About half of the samples, the result of microbiological tests were positive. In this study, various bacteria grew in the prepared samples, with the most prevalent being $P$. acnes (18\% of cases), and the rest were coagulase-negative staphylococcus or Gram-negative bacilli. In $33 \%$ of the positive samples, inflammatory multinucleate cells were observed, which can confirm an underlying inflammatory trend in patients with positive results (20).

In another study, the researchers believed that the results of other studies may be due to contamination, emphasizing that their samples were prepared in carefully sterilized conditions. Of the 120 samples collected, 116 samples were sterilized and only in 4 cases coagulase-negative staphylococcus grew, indicating the contamination of the samples. Results of this study cast doubts on the role of bacteria such as $P$. acnes in creating MC and infection of the lumbar disc by this bacterium (21). Of course, the results of the present study and those of others reporting that only $P$. acnes was found may be evidence rejecting the samples contamination as a source for positive culture.

To confirm contamination as a source for $P$. acnes in lumbar disc, some researchers went even farther and claimed with more evidence that the presence of $P$. acnes is solely due to contamination of the samples. In the study by Carricajo et al. on 54 patients with herniated disc, only in three cases $P$. acnes was positive in culture. In this study, to examine other sources of contamination with $P$. acnes, the samples were simultaneously taken from the flavum ligaments, adjacent muscles, and the operating room air. Of the three patients with positive lumbar disc culture, in two cases the culture of muscle and flavum ligament samples was also positive (22). It must be noted that, in 10 patients with negative lumbar disc samples, the muscle and ligament cultures were positive. For all three patients with lumbar disc samples, the operating room air control sample was positive, but in one case for whom the disc biopsy was negative, the operating room air culture was still positive for P. acnes.

Results reported by Aghazadeh et al. showed that, from the 120 patients, 87 cases of MC were herniated disk, and in 36 cases the $P$. acnes was positive (23). The results of a study conducted by Salehpour et al. also is confirmatory to the present study. They showed that, $60(50 \%)$ samples were infected by different bacteria, of which $76.66 \%$ of infections were related to the anaerobic bacterium $P$. acnes. He stated that, the presence of $P$. acnes in lumbar disc herniation is a one of the suspected elements leading to this disease (24). In another study, Zhou et al. showed that 11 discs and 3 muscle samples were positive for $P$. acnes. As a result, it has been confirmed that $P$. acnes growth in the muscle is related to contamination (25). Also, in a recent study by Javanshir et al. it was shown that there is a positive relation between $P$. acnes and Modic changes and presence of $P$. acnes (26).

\section{CONCLUSION}

The present study showed that in over half of the patients with IVD hernia and MC based on MRI, the anaerobic $P$. acnes grows in the disc sample. The presence of this bacterium and the inflammatory condition resulting from its growth may be underly- 
ing causes for these changes.

In summary, the review of the literature shows that contradictory results have been reported on IVD infection with $P$. acnes. Although no other organism was evaluated in this study, it is suggested that future studies more precisely examine contamination as a source for $P$. acnes genome.

\section{ACKNOWLEDGEMENTS}

This article is taken from a student dissertation sponsored by the Vice President of Research and Technology of the Aja Medical Sciences University. We would like to thank all the contributors who contributed to this study.

\section{REFERENCES}

1. Mehrdad R, Shams-Hosseini NS, Aghdaei S, Yousefian M. Prevalence of low back pain in health care workers and comparison with other occupational categories in Iran: a systematic review. Iran J Med Sci 2016;41: 467-478.

2. Fatoye F, Gebrye T, Odeyemi I. Real-world incidence and prevalence of low back pain using routinely collected data. Rheumatol Int 2019;39: 619-626.

3. Jensen T, Karppinen J, Sorensen J, Niinimäki J, Leboeuf-Yde C. Vertebral endplate signal changes (Modic change): A systematic literature review of prevalence and association with non-specific low back pain. Eur Spine J 2008;17:1407-1422.

4. Albert HB, Manniche C. Modic changes following lumbar disc herniation. Eur Spine J 2007;16:977-982.

5. Modic M, Steinberg P, Ross J, Masaryk T, Carter J. Degenerative disk disease: assessment of changes in vertebral body marrow with MR imaging. Radiology 1988;166:193-199.

6. Albert HB, Kjaer P, Jensen TS, Sorensen J, Bendix T, Manniche C. Modic changes, possible causes and relation to low back pain. Med Hypotheses 2008;70:361368.

7. Stirling A, Worthington T, Rafiq M, Lambert PA, Elliott TS. Association between sciatica and Propionibacterium acnes. Lancet 2001;357:2024-2025.

8. Wang E, Lee J S-S, Hee T H. Is Propionibacterium acnes associated with hair casts and alopecia? Int $J$ Trichol 2012; 4: 93-97.

9. Bhanji S, Williams B, Sheller B, Elwood T, Mancl L. Transient bacteremia induced by toothbrushing: a com- parison of the Sonicare toothbrush with a conventional toothbrush. Pediatr Dent 2002;24:295-299.

10. Farrar MD, Ingham E. Acne: inflammation. Clin Dermatol 2004;22:380-384.

11. Cunha C, Silva AJ, Pereira P, Vaz R, Gonçalves RM, Barbosa MA. The inflammatory response in the regression of lumbar disc herniation. Arthritis Res Ther 2018;20: 251.

12. Albert HB, Sorensen JS, Christensen BS, Manniche C. Antibiotic treatment in patients with chronic low-back pain and vertebral bone edema (Modic type 1 changes): a double-blind randomized clinical controlled trial of efficacy. Eur Spine J 2013; 22:697-707.

13. Albert HB, Lambert P, Rollason J, Sorensen JS, Worthington $\mathrm{T}$, Pedersen $\mathrm{MB}$, et al. Does nuclear tissue infected with bacteria following disc herniations lead to Modic changes in the adjacent vertebrae? Eur Spine $J$ 2013;22:690-696.

14. Sfanos KS, Isaacs WB. An evaluation of PCR primer sets used for detection of Propionibacterium acnes in prostate tissue samples. Prostate 2008;68:1492-1495.

15. Ishige I, Usui Y, Takemura T, Eishi Y. Quantitative PCR of mycobacterial and propionibacterial DNA in lymph nodes of Japanese patients with sarcoidosis. Lancet 1999;354:120-123.

16. Agarwal V, Golish SR, Alamin TF. Bacteriologic culture of excised intervertebral disc from immunocompetent patients undergoing single level primary lumbar microdiscectomy. J Spinal Disord Tech 2011; 24:397400.

17. Rollason J, McDowell A, Albert HB, Barnard E, Worthington T, Hilton AC, et al. Genotypic and antimicrobial characterisation of Propionibacterium acnes isolates from surgically excised lumbar disc herniations. Biomed Res Int 2013;2013:530382.

18. Uckay I, Dinh A, Vauthey L, Asseray N, Passuti N, Rottman M, et al. Spondylodiscitis due to Propionibacterium acnes: report of twenty-nine cases and a review of the literature. Clin Microbiol Infect 2010;16:353-358.

19. Wedderkopp N, Thomsen K, Manniche C, Kolmos HJ, Secher Jensen T, Leboeuf Yde C. No evidence for presence of bacteria in Modic type I changes.Acta Radiol 2009;50:65-70.

20. Arndt J, Charles YP, Koebel C, Bogorin I, Steib J-P. Bacteriology of degenerated lumbar intervertebral disks. J Spinal Disord Tech 2012;25:E211-216.

21. Ben-Galim P, Rand N, Giladi M, Schwartz D, Ashkenazi E, Millgram M, et al. Association between sciatica and microbial infection: true infection or culture contamination? Spine (Phila Pa 1976) 2006; 31:2507-2509.

22. Carricajo A, Nuti C, Aubert E, Hatem O, Fonsale N, Mallaval F, et al. Propionibacterium acnes contamination in lumbar disc surgery. $J$ Hosp Infect 2007;66:275277. 
23. Aghazadeh J, Salehpour F, Ziaeii E, Javanshir N, Samadi A, Sadeghi J, et al. Modic changes in the adjacent vertebrae due to disc material infection with Propionibacterium acnes in patients with lumbar disc herniation. Eur Spine J 2017;26:3129-3134.

24. Salehpour F, Aghazadeh J, Mirzaei F, Ziaeii E, Alavi SAN. Propionibacterium acnes infection in disc material and different antibiotic susceptibility in patients with lumbar disc herniation. Int J Spine Surg 2019;13:146-152.

25. Zhou Z, Chen Z, Zheng Y, Cao P, Liang Y, Xingkia Z, et al. Relationship between annular tear and presence of Propionibacterium acnes in lumbar intervertebral disc. Eur Spine J 2015;24:2496-2502.

26. Javanshir N, Salehpour F, Aghazadeh J, Mirzaei F, Naseri Alavi SA. The distribution of infection with Propionibacterium acnes is equal in patients with cervical and lumbar disc herniation. Eur Spine J 2017;26:31353140 . 